\title{
B.г. ЗИНОВ,
}

д.э.н., главный научный сотрудник Центра научно-технической экспертизы ИПЭИ РАНХиГС при Президенте РФ, г. Москва, Россия, zinov-v@yandex.ru

\section{О.А. ЕРЁМЧЕНКО,}

старший научный сотрудник Центра научно-технической экспертизы ИПЭИ РАНХиГС при Президенте РФ, г. Москва, Россия, tatrics@mail.ru

\section{КОРПОРАТИВНЫЕ ВЕНЧУРНЫЕ ИНВЕСТИЦИИ: ОСОБЕННОСТИ И УСПЕШНЫЕ ПРАКТИКИ}

\footnotetext{
I УДК 330.3

Зинов В.Г., Ерёмченко О.А. Корпоративные венчурные инвестиции: особенности и успешные практики (Центр научно-технической экспертизы ИПЭИ РАНХиГС при Президенте РФ, пр. Вернадского, д. 82, г. Москва, Россия, 179571 )

Аннотация. В обзоре отечественных и зарубежных публикаций приведены успешные практики корпоративного венчурного инвестирования, которые позволяют уточнить критерии устойчивости I и требования для достижения стабильного функционирования корпоративных фондов. Показано, I что принципиальное значение имеет согласованность цели фонда с целями материнской компании, 1. непрерывность функционирования, преемственность в отношении стратегии, инвестиционного фокуса I и основной команды, а также финансовая устойчивость, позволяющая быть стабильным партнером портфельным компаниям в течение всего их жизненного цикла. Подчеркивается, что корпоративные в венчурные инвестиции не являются инструментом финансовых спекуляций, и созданный венчурный фонд I необходим материнской компании, прежде всего, как инструмент поиска, развития, трансфера технологий.

- Рассмотрены основные отличия корпоративных и, так называемых, независимых венчурных фондов,

- отражающие различные цели, сферы деятельности, источники финансирования, правовой статус, системы вознаграждения менеджмента и подотчетность.

I Ключевые слова: корпоративное венчурное инвестирование, венчурный капитал, венчурный фонд, I корпоративный венчурный фонд, стартапы, сделки слияния и поглощения, тренды.

DOI 10.22394/2410-132X-2019-5-3-170-184

1 Цитирование публикации: Зинов В.Г., Ерёмченко О.А. (2019) Корпоративные венчурные инвестиции: особенности I и успешные практики // Экономика науки. Т. 5. № 3. С. 170-184.
}

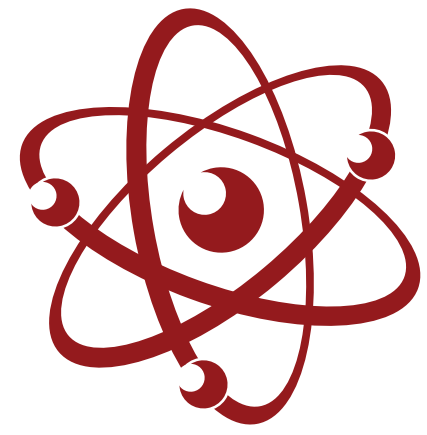

(C) В.Г. Зинов, О.А. Ерёмченко, 2019 г.

\section{ВВЕДЕНИЕ}

И нновации всегда были ключом к развитию и процветанию корпораций. Однако классический внутренний процесс разработки новых продуктов и услуг зачастую бывает затратным и громоздким. Поэтому постепенно появляются альтернативные формы освоения инноваций через внешние инвестиционные обязательства, которые могут оказаться успешными в случае квалифицированного управления со стороны корпорации, чтобы в конечном счете стать источником кратко- или долгосрочных возможностей для ее развития. Подобные стратегические технологические альянсы с малыми и средними компаниями, обладающими сильным потенциалом роста, позволяют обеспечить доступ к новым возможностям развития корпорации.

\footnotetext{
Публикация подготовлена в рамках Государственного задания ФГБУ ВПО «Российская академия народного хозяйства и государственной службы при Президенте Российской Федерации» на 2019 год по проекту № 1.3 «Корпоративные венчурные фонды как инструмент инновационного развития российских корпораций».
} 
С этой целью все чаще создаются венчурные фонды, как подразделения или дочерние компании, входящие в структуру корпораций, так называемые корпоративные венчурные фонды (КВФ). Они позволяют осуществлять технологическое развитие не только за счет проведения внутрикорпоративных НИОКР, но и путем освоения готовых инноваций, полученных извне.

По данным ежегодного отчета Global CVC Report, содержащего анализ корпоративных венчурных инвестиций, финансирование КВФ в 2018 г. увеличилось примерно на 47\% по сравнению с 2017 г., а объем сделок возрос на $32 \%$ за тот же период [1].

Тема необходимости развития корпоративных венчурных инвестиций в нашей стране впервые была поднята в 2011 г. в поручениях Президента Российской Федерации, выданных по результатам заседания Комиссии по модернизации и технологическому развитию экономики России [2].

Новый импульс процессу формирования отечественного рынка корпоративных венчурных инвестиций придали опубликованные в августе 2014 г. «Поручения по итогам встречи с членами Экспертного совета при Правительстве и представителями экспертного сообщества по вопросу развития инноваций» [3]. Они предусматривают выработку предложений «по развитию системы корпоративных венчурных фондов, осуществлению инвестиций в отраслевые фонды или институты развития, а также по вопросам приобретения инновационных компаний, ведущих инновационные разработки, в рамках осуществления программ инновационного развития государственных корпораций и компаний с государственным участием».

В 2018 г. стала заметна готовность крупнейших российских компаний развиваться за счет венчурных инвестиций в стартапы. В исследовании РВК было показано, что участие корпораций стало главным событием в российской венчурной индустрии в прошлом году. Несмотря на то, что корпоративные венчурные инвестиции в 2018 г. составили всего 8570,7 млн. руб. (32\% от общего объема российского венчурного рынка), за год корпоративный венчурный сектор вырос в 7 раз [4].
Опыт первых КВФ как инструмента технологического развития российских компаний только начинает становиться предметом исследований. Недостаток отечественных исследований, подтверждающих или опровергающих мнения об эффективности корпоративного венчурного инвестирования, в значительной мере, связан с закрытостью данных о деятельности КВФ. В открытом доступе нет российских баз данных, которые включали бы в себя начальные показатели по инвестируемым компаниям (размер выручки, активов, возраст фирмы, количество выпущенных патентов и т.д.). Вместе с тем, создание сектора корпоративного венчурного капитала в Российской Федерации может стать эффективным инструментом достижения глобальной конкурентоспособности отечественной промышленности за исторически короткий промежуток времени. Поэтому целью настоящего исследования является обзор публикаций об особенностях и наиболее успешных практиках зарубежных корпоративных венчурных фондов.

\section{ОСОБЕННОСТИ КОРПОРАТИВНЫХ ВЕНЧУРНЫХ ФОНДОВ}

Мотивацией для создания КВФ чаще всего является использование еще одного инструмента инновационной деятельности, направленного на поиск успешных бизнес-идей и технологий. В разрабатывающих такие технологии малых инновационных компаниях приобретается доля в уставном капитале, используется управленческий и маркетинговый опыт инвестирующей корпорации (материнской компании), что приводит к увеличению конкурентных преимуществ и стимулированию взаимного роста.

$\mathrm{KBФ} \mathrm{являются} \mathrm{инструментом} \mathrm{повышения}$ конкурентоспособности как инвестируемой компании, так и инвестирующей корпорации. Поэтому при подобных инвестициях менеджмент обычно стремится к продвижению, в первую очередь, стратегических, а не только финансовых целей. Этот тезис еще не в полной мере осознан в российских компаниях, менеджмент крупных корпораций задается вопросом: как можно создавать фонд и не ставить перед ним, прежде всего, финансовые цели? 
Промышленные компании обычно функционируют в определенной рыночной нише, развивают соответствующие компетенции, потому они не обладают достаточной квалификацией, чтобы действовать в качестве финансовых спекулянтов. Стратегически ориентированные инвестиции осуществляются в первую очередь для увеличения, прямо или косвенно, продаж и прибыли действующего бизнеса материнской компании, а не инвестируемого стартапа, стремясь использовать синергию между компанией инвестором и стартапом. Потому перед КВФ ставится основная цель - использовать потенциал портфельных компаний для дополнительного роста корпорации, например, если компания-инвестор захотела получить доступ к новым технологиям, ресурсам и рынкам. Таким образом, если речь идет о финансовых результатах таких инвестиций, то только опосредовано вследствие освоения новых технологий и рынков.

В недавнем эмпирическом исследовании В. Костеева и В. Сидорович (2016) [5] были рассмотрены сделки европейских КВФ. Результаты показали, что 54\% европейских материнских компаний инвестируют в основном по стратегическим причинам в связи с имеющимися финансовыми проблемами, 33\% инвестируют в основном по финансовым причинам, в связи с имеющимися стратегическими проблемами, и 13\% инвестируют с исключительно финансовыми целями. Таким образом, стратегические и финансовые причины, как правило, тесно взаимосвязаны и не противоречат друг другу.

Второй отличительной чертой корпоративных венчурных инвестиций является возможность портфельных компаний использовать заводы-изготовители, каналы распределения, технологии, отработанные методы ведения бизнеса компании-учредителя фонда для создания, продажи или обслуживания новых продуктов. Целью инвестиций может стать проверка, в какой степени различные новые технологические, организационные и маркетинговые возможности инвестируемой компании могут развивать или угрожать жизнеспособности существующего бизнеса. По данным [6] многие корпорации уточняют, развивают и закрепляют свои стратегии в венчурных инвестиционных портфелях.
Если они не могут победить быстрорастущие малые и средние компании в конкурентной борьбе, то становятся их финансовыми партнерами в бизнесе.

Как показывают результаты опроса менеджеров КВФ [7], перед ними, в первую очередь, поставлены задачи, которые непосредственно связаны с развитием рыночных, технологических, производственных, исследовательских компетенций материнской компании. Разумеется, все направлено на будущие финансовые результаты, но задача заработать для корпорации дополнительную прибыль в краткосрочном периоде не ставится.

Одной из основных отличительных черт корпоративного венчурного финансирования является то, что финансовый капитал при инвестировании в инновационный стартап дополняется разнообразным промышленным опытом. Выделяют пять групп стимулов для участия в корпоративных венчурных сделках [8]:

- Технологический интерес. инвестирование в инновационные компании в направлении, котором работает материнская компания, позволяет отслеживать инновации и приводит к экономии средств на выполнение внутренних НИОКР. Корпорации при этом могут достигать технологических прорывов путем подписания соглашений о разработке совместных проектов, передачи и приобретения лицензий или приобретения стартапа на более поздней стадии разработки и продвижения инновации на рынок. Происходит интеграция целей инвестирующей и инвестируемой компаний вплоть до их возможного объединения.

- Повышение ценности собственных НИОКР: поддержка создания развивающихся стартапов позволяет корпорации развивать их патентные портфолио. При этом большая часть созданных объектов интеллектуальной собственности часто не используются стартапами, а корпорации имеют возможность при необходимости заключить лицензионные соглашения на эти объекты в приоритетном порядке.

- Отслеживание рынка и приобретение опыта на новых рынках. финансирование стартапов предоставляет инвесторам информацию о поведении клиентов по отношению к новым продуктам и их обслуживанию, которая может 
быть использована для того, чтобы начать выпуск подобных товаров и оказание услуг.

- Внедрение новых практик. инвестируемые стартапы используются в качестве инструмента для того, чтобы внедрить новые практики в области внешних коммуникаций (взаимодействия с клиентами и поставщиками) и внутренних взаимоотношений между сотрудниками, руководством и персоналом, структурными подразделениями, которые в дальнейшем могут быть использованы корпорацией в случае успеха.

- Финансовый интерес. как и другие венчурные инвесторы, корпорации должны преумножить свои инвестиции, получив доход на момент выхода через выплаты дивидендов, если выращенный стартап не представляет интереса для материнской компании.

По этим причинам корпоративные венчурные инвестиции часто определяются как вклад финансовых, технических ресурсов и стратегических экспертных знаний в начальный этап предпринимательства. Это подчеркивает взаимозависимость, которая возникает между инвестируемым стартапом и корпорацией. Таким образом, анализ зарубежных публикаций показывает, что доминирует стратегический подход, который в первую очередь характерен для КВФ - отбирать и финансировать проекты, имеющие синергию с собственным бизнесом корпорации.

Вместе с тем, организационные изменения, вытекающие из корпоративных венчурных программ, не всегда позитивны как для инвестируемых стартапов, так и для материнской компании. Поэтому необходимо упомянуть о проблемах, возникающих при использовании венчурных инвестиций, к которым следует отнести:

- Во-первых, трудности сохранения целостности управленческих решений по отношению к проектам, которые конкурируют с аналогичными проектами материнской компании.

- Во-вторых, уступки экономическому и стратегическому выбору первых руководителей материнской компании. Капитал часто поступает из ее избыточной ликвидности, поэтому инвестирование в поддерживаемые проекты в период экономического спада может прекратится. Может возникнуть риск закрытия таких проектов при смене руководства корпорации и, соответственно, риск потерь вложенных ранее инвестиций.

Кроме этого предпринимательский подход, характерный для венчурного инвестора, вступает в противоречие с организационными процедурами, сложившимися в практике компании-инвестора, консервативной финансовой политикой и стилем управления.

\section{ОТЛИЧИЯ КОРПОРАТИВНЫХ И НЕЗАВИСИМЫХ ВЕНЧУРНЫХ ФОНДОВ}

Основной целью корпоративного венчурного капитала являются технологическое предпринимательство, т.е. получение быстрого доступа к новым технологиям, которые могут резко изменить структуру отрасли и являются одновременно и потенциальной угрозой, и источником дохода для рыночных лидеров. Поэтому при сравнении КВФ с традиционными институциональными (независимыми) венчурными фондами (НВФ), созданными частными инвесторами, можно выделить немало отличий.

Прежде всего, КВФ в большей степени включен в текущую деятельность компаний своего инвестиционного портфеля в отличии от НВФ, специализирующихся на венчурном капитале исключительно для получения прибыли от инвестиций, менеджмент которого редко вмешивается в повседневную работу и процесс принятия решений в финансируемом стартапе.

Кроме этого, средства корпоративных и независимых венчурных фондов имеют ряд институциональных особенностей, потому существенно отличаются по структуре, юридическому статусу и бизнес-модели.

КВФ, как правило, представляют собой автономные филиалы нефинансовых корпораций и инвестируют в новые предприятия от имени учредителей, пользуются почти неограниченным жизненным периодом, а также способны при необходимости привлекать дополнительный капитал материнской компании.

Напротив, НВФ являются профессиональными инвесторами, нацеленными на получение дохода в виде прироста стоимости инвестируемых компаний и используют широкий спектр внешних по отношению к управляющей 
компании источников финансирования (пенсионные фонды, банки, корпорации, независимые инвесторы, государство и т.д.). НВФ обычно структурированы как ограниченные партнерства (в России - инвестиционные товарищества) с подотчетностью инвесторам, вложившим средства в фонд, и ограничены договором на десятилетний срок (с вариантом продления не более чем на два года). Привлечение средств НВФ ограничено размером капитала, первоначально выделенного их партнерами.

Более длительные инвестиционные горизонты и относительно неограниченное предложение капитала КВФ позволяют им быть более открытыми для экспериментов, они могут инвестировать в долгосрочные инновационные проекты, которые, как правило, не готовы генерировать финансовые доходы в краткосрочном периоде, но могут иметь высокий потенциал роста.

КВФ и НВФ используют различные управленческие практики стимулирования и вознаграждения. Структура вознаграждения менеджеров НВФ определяется исходя из результатов деятельности как часть прибыли фонда при его выходе из инвестируемой компании и капитала, выделяемого на ведение текущей деятельности. Этот подход существенно отличается от принятого в КВФ, где менеджеры получают фиксированную заработную плату и бонусы, привязанные к финансовой эффективности корпорации. Вознаграждение менеджмента КВФ выплачивается из фонда оплаты труда, выделенного корпорацией, а также в форме процента от инвестируемого капитала и вознаграждения при развитии инвестируемых компаний.

Такие различия между КВФ и НВФ позволяют корпоративным фондам быть более открытыми для экспериментов и случайных неудач в портфельных компаниях, что крайне необходимо для мотивации успешных инноваций.

По данным опроса 2000 г., проведенного в исследовании [9], большинство КВФ (68\% респондентов) не пользуются мощными схемами вознаграждения, основанными на результатах деятельности, которые стандартны для НВФ. Вместо этого менеджеры корпоративных фондов обычно получают фиксированную зарплату и годовые бонусы. Как было отмечено в исследовании [9], почти ни один из КВФ не следует традиционной модели деятельности венчурных фондов, выражающейся в требованиях к сотрудникам выступать в качестве соинвесторов.

В исследовании [10] сделан вывод, что отсутствие мощных схем стимулирования позволяет менеджерам корпоративных фондов быть более терпимыми к неудачам и, следовательно, лучше развивать инновации. С другой стороны, тот факт, что вознаграждение менеджеров таких фондов обязательно связано с продвижением интересов корпоративных родителей за счет инвестируемых компаний, может, в свою очередь, препятствовать инновациям в таких корпорациях. Это может помочь корпорации лучше мотивировать КВФ проводить эксплуататорские, а не воспитательные стратегии в направлении инвестируемых компаний.

В отличие от работы с НВФ, при получении поддержки от КВФ стратап может воспользоваться преимуществами материнской компании, в том числе, каналами распределения, технологиями, и бизнес-практиками для создания, продажи или обслуживания своей продукцией. Согласно [11] корпоративный родитель, получая от стартапа доступ к новый технологии и рынкам для улучшения существующего бизнеса, со своей стороны предоставляет ему используемые в своей практике уникальные знания отрасли и технологии. Очевидно утверждение, что КВФ имеют конкурентное преимущество перед НВФ в связи С их превосходством в знании рынков и технологий, несомненной способностью быть долгосрочным инвестором, передавая также «мягкую» информацию, связанную с проектами материнской компании в области исследований и разработок. Это невозможно достичь в условиях инвестиций и управления НВФ.

Если рассматривать преимущества КВФ перед другими формами организации инновационной деятельности корпораций, исследователи отмечают такие аспекты как: поддержка предпринимательских инициатив [12], организационное обучение [13], возможности поддержки со стороны руководства корпорации, причем не только финансовой. Вместе взятые, вышеуказанные факторы обеспечивают КВФ большую эффективность, чем НВФ в развитии инноваций в своих портфельных компаниях. 
Вместе с тем, есть опасность того, что КВФ будут стимулировать в большей степени использование и развитие глубоких отраслевых и технологических знаний корпоративных родителей, вместо того, чтобы выращивать инвестируемые стартапы, что, как правило, препятствует развитию инноваций. В исследовании [14] моделируется ситуация, в которой предприниматели чаще ищут финансирование у НВФ вместо КВФ из-за боязни быть эксплуатируемыми материнскими компаниями, особенно в случае, если их стартапы находятся в потенциальной конкуренции с корпоративными инвесторами на товарном рынке. Это объясняется тем, что НВФ могут быть более эффективными, самостоятельно распределяя ресурсы, поскольку они структурированы как партнерства с ограниченной ответственностью и имеют полный контроль над капиталом, предоставленном учредителями. Кроме того, независимые фонды преследуют чисто финансовую отдачу, и их управляющие вознаграждаются только на основе финансовых показателей. Поэтому более эффективное распределение ресурсов, более высокая приведенная в действие система вознаграждения и специализированная отраслевая экспертиза могут сделать НВФ превосходящими КВФ при выращивании инноваций.

Для того, чтобы сделать вывод о том, КВФ или НВФ быстрее выращивают инновации, в исследовании [15] были рассмотрены результаты первичного публичного размещения акций (IPO) компаний, поддерживаемых КВФ по сравнению с теми, в которые инвестирует НВФ. Авторы выделили 562 венчурных фонда, которые аффилированы с публичными материнскими компаниями. Для измерения инновационной деятельности инвестируемых ими стратапов, согласно принятой в научной литературе практике (например, [16]), были использованы патентные показатели. В отличие от расходов на исследования и разработки патентные показатели отражают как фактическую инновационную продукцию, так и оценку эффективности использования инноваций. Для выборки были отобраны только те компании, которые вышли на IPO с действующими патентами.

В качестве информационной основы исследования были использованы данные при анализе двух показателей выпуска инновационной продукции:

- количество полученных патентов, как измерение «количества» инноваций;

- количество цитирований, полученных патентами, как измерение «качества» нововведения.

В результате исследования было обнаружено, что портфельные компании КВФ, по сравнению с компаниями, поддержанными НВФ, производят большее количество патентов и большее количество патентов высокого качества. В частности, компании КВФ производят на 20-40\% (в среднем 26,9\%) больше патентов за три года до IPO и на 38\%-60\% больше патентов после IPO, и эти патенты получают на 17,6\% больше цитирований. В первые четыре года после IPО, в том числе в год IPO, компании КВФ производят на 44,9\% больше патентов, которые получают на 13,2\% больше цитирований в будущем. Таким образом компании, получившие корпоративные инвестиции, создают более востребованные технические решения перед выходом на IPO и после IPO, чем компании, поддерживаемые НВФ.

Результаты анализа показали, что портфельные компании КВФ, характеризуются в среднем на 25\% более высоким выходом инноваций до IPO и в среднем на 45\% большим количеством инноваций после выхода на IPО. Хотя и нельзя полностью исключить «эффект отбора» компаний для инвестиций, эти различия с большей вероятностью можно отнести на счет развития инноваций. Несомненно, КВФ имеют высокую способность поддерживать рост эффективных новшеств в поддержанных стартапах.

\section{ТРЕБОВАНИЯ ДЛЯ УСТОЙЧИ- ВОСТИ КОРПОРАТИВНОГО ВЕНЧУРНОГО ФОНДА}

В научной литературе, посвященной изучению КВФ, отмечается, что все чаще корпоративные венчурные инвестиции становятся инструментом повышения ценности компании через достижение стратегических задач, в том числе диверсификации основных видов деятельности [17].

В 2009 г. компанией Ernst and Young был проведен опрос 37 компаний, которые 
использовали корпоративный венчурный капитал для повышения своей конкурентоспособности путем освоения новых продуктов, новых рынков и других перспективных для компании аспектов развития [7]. Основными стратегическими целями, которые указали респонденты анкетирования, стали выявление новых инноваций для технологического развития, а также получение окон для новых рыночных возможностей.

Корпоративное венчурное финансирование признано обучающей инвестиционной стратегией через создание динамических возможностей для будущих изменений [18]. При создании КВФ головной компанией признается необходимость использования внешних источников знаний, а также трансфера технологической информации. Несмотря на барьеры передачи знаний, в том числе возможные разногласия между инвесторами и стартапами, у портфельных компаний появляется больше возможностей для развития, если она участвует в инновационном обмене информацией в открытом формате с инвестором [19]. Благодаря открытому обмену и увеличению собственных возможностей, материнские организации и стартапы имеют возможность значительно ускорить продвижение конкретных технологий.

В исследовании [20] обосновано три требования для достижения стабильного функционирования КВФ: стратегические цели, непрерывность и финансовая устойчивость, причем третье требование является наиболее критичным.

\section{Стратегическая цель}

В отличие от единственного фокуса на финансовых доходах, общего для всех НВФ, большинство КВФ должны, прежде всего, добиваться стратегических целей, поставленных корпорацией. В погоне за прибылью в результате типичных для венчурных инвесторов финансовых спекулятивных операций могут быть пропущены технологические тенденции стратегического значения, что может обесценить всю деятельность КВФ. Опрос членов NVCA (Американская национальная ассоциация венчурного капитала National Venture Capital Association), опубликованный в 2012 г., показывает, что стратегическое направление является основой для 95\% опрошенных менеджеров КВФ [11]. Кроме того, около 75\% опрошенных более высоко оценивают достижение стратегических целей на уровне или выше, чем получение финансовой прибыли. Тем не менее, достижение финансовых целей не является взаимоисключающим и противоречащим достижению стратегической ценности.

Непрерывность

Венчурное финансирование - это специфическая сфера деятельности, где многое зависит от хорошей репутации и лично полученной информации из надежных источников. Любой инвестор, независимый или корпоративный, должен стремиться стать надежным и устойчивым партнером как для стартапов, так и для других инвесторов. Следовательно, первой предпосылкой для создания успешной программы КВФ является преемственность в отношении стратегии, инвестиционного фокуса и основной команды. Команды для осуществления корпоративного венчурного инвестирования формируются частично за счет специалистов материнской компании, которые проходит регулярную корпоративную ротацию каждые 3-5 лет, и приглашенных специалистов, которые получают опыт работы в КВФ в течение ограниченного времени. Костяк команды фонда имеет важное значение для обеспечения преемственности внешней группы (предприниматели, портфельные компании), а также для внутренней группы менеджеров.

Финансовая устойчивость

Финансовая устойчивость - ключевое требование успешности КВФ. Необходимо активное взаимодействие с проинвестированными стартапами (особенно при инвестировании в технологии на ранней стадии), в течение всего жизненного цикла (в среднем более восьми лет). Долгосрочная устойчивость в корпоративной среде может быть достигнута только в том случае, если КВФ как структура материнской организации не потеряет деньги в течение более длительного периода времени, поскольку корпорации могут сокращать программы из-за их убыточности, особенно во время кризиса. Ничто не остается стратегической ценностью очень долго, если не дает финансовых результатов, но если программы КВФ не имеют стратегических целей, то также становятся ближе к сокращению во время финансовых кризисов. 
Ценность обучения корпорации

Только 6 из 20 опрошенных менеджеров КВФ отметили, что их корпорация понимает суть корпоративного венчурного инвестирования. Большинство опрошенных заявили, что контролирующие их деятельность сотрудники корпорации должны быть обучены особенностям венчурного инвестирования. Это весьма важный вывод, и в некоторых случаях непонимание сотрудников корпорации может помешать менеджерам КВФ использовать весь свой потенциал. Проблема в том, что венчурный капитал и стартапы фокусируются на финансовом успехе, а не на развитии прорывных инноваций. При таком непонимании на корпоративном уровне КВФ может быть ориентирован на инвестиции в неэффективные инновации. Согласно данным исследования [20], в некоторых случаях менеджерам КВФ приходилось управлять процессом своего целеполагания самостоятельно из-за отсутствия корпоративного понимания процесса венчурного инвестирования.

Характерно такое непонимание места и роли КВФ в инновационной системе в настоящее время для российских корпораций. Приглашаемые в корпорации менеджеры создаваемых КВФ, имеющие ранее опыт работы в независимом венчурном фонде, не получают ясного целеполагания новой деятельности и им не понятно, зачем увеличивать ценность инвестируемого стартапа, если его все-равно нужно покупать, а покупать активы целесообразно при минимальной стоимости.

\section{УСПЕШНЫЕ ПРАКТИКИ КОРПОРАТИВНЫХ ВЕНЧУРНЫХ ИНВЕСТИЦИЙ}

Корпорация и ее фонд должны обеспечить сбалансированный подход к включению как стратегических, так и финансовых целей в корпоративный риск. Каждый новый участник, при желании воспользоваться жизненно важной для него инновационной системой взаимодействия с корпорацией, должен зарекомендовать себя в качестве ее жизнеспособного и долгосрочного партнера. Нужно учитывать, что фокус на финансовые результаты создает хорошую репутацию в рамках корпорации и всегда высоко ценится.
Имеется две пары измерений корпоративного венчурного инвестирования:

- стратегическое или финансовое целеполагание инвестиций;

- сильная или слабая связь с материнской компанией.

Очевидно, что эти две пары параметров не являются единственными для обоснования принятия управленческих решений, большинство решений об инвестициях будет, как правило, попадать между этими парами характеристик.

В исследовании [21] на конкретных примерах проведен анализ сочетания оценки корпоративной цели материнской компании (стратегической или финансовой) со степенью связи (сильной или слабой) между деятельностью корпорации и получающим финансирование стартапом. Это позволило выделить четыре типа управленческих решений при корпоративных венчурных инвестициях.

Первый, управляющий тип корпоративных венчурных инвестиций (инвестиции-двигатели развития текущего бизнеса учредителя фонда) характеризуется стратегическим обоснованием и тесной связью между стартапом и деятельностью материнской компании.

В исследовании [21] приводятся примеры такого типа корпоративных венчурных инвестиций. Фонд Agilent Technologies инвестировал в соответствии с принятыми целям перспективного развития материнской компании в науки о жизни, беспроводные коммуникации и оптические коммуникации. Основная задача фонда - развитие максимального сотрудничества со структурами корпорации для подключения инвестируемых компаний к существующим планам. Например, были уточнены инвестиционные возможности для стартап-компании, создающей беспроводные радиочастотные устройства, ставилась задача проверить, насколько новый бизнес будет успешным при переносе в корпорацию. Инвестиции становятся формой проверки, стоит ли продолжать начатое направление. При неудаче материнская компания Agilent получит информацию о реальных рисках и барьерах развития нового бизнеса.

Другой аналогичный пример приведен в исследовании [21] о венчурных инвестициях корпорации Microsoft, вложившей более 1 млрд. 
долл. в стартапы для проработки будущего продвижения своей новой интернет-архитектуры «.Net». В случае успеха использования новой платформы у Windows возникала возможность устанавливать стандарты для последующего поколения продуктов через интернет, что позволяло расширить разнообразие услуг. Финансируя начинающие компании с целью использования ими своей архитектуры по стандарту Microsoft, корпорация будет способствовать более быстрому распространению своего нового стандарта по сравнению с конкурентами Sun Microsystems и IBM. Инвестируемые стартапы связаны с Microsoft с помощью предоставленного им для разработки собственных продуктов программного обеспечения и средств Windows. Решение корпорации обусловлено стратегической ценностью. Net-инвестиций, и Microsoft, войдя в новые инвестиции, увидела возможность выиграть конкуренцию за стандарт интернет услуг следующего поколения.

Разумеется, всегда принятие решений о корпоративных венчурных инвестициях непосредственно связано с реализацией корпоративной стратегии, однако у этого подхода есть ограничения. Обязательно у такого типа инвестиций должна быть неразрывная взаимосвязь с бизнес процессами материнской компании, что выражается в том, что финансовые средства будут поддерживать ее текущую деятельность. Очень важно не перейти грань, когда корпорации в поиске новых возможностей придется столкнуться со стратегиями, оказывающими разрушительные последствия для реализации своих планов. Важно определить, когда материнская компания в поиске путей повышения конкурентоспособности может выйти за пределы своих текущих возможностей, чтобы ответить на внешние вызовы. Потому что превзойти реализуемую стратегию и сложившие процессы, как правило, нельзя, можно только полагаться на стимулирование инвестиций, которые тесно связаны с текущими процессами. Венчурные инвестиции лучше всего подходят для задач поиска новой стратегии.

Широко используется второй, стимулирующий тип корпоративных венчурных инвестиций, когда фонд принимает решения об инвестициях хоть и по стратегическим причинам, но не планирует тесной взаимосвязи портфельной компании с текущими процессами материнской компании. Целью таких инвестиций становится создание для корпорации комфортной рыночной среды (работа с поставщиками, покупателями), которая бы содействовала увеличению спроса на выпускаемую продукцию. Такие инвестиции без операционной связи между стартапом и корпорацией в случае успеха нового бизнеса принесут выгоду, если имеется комплиментарность бизнесов стартапа и материнской компании. Например, если прогнозируется продуктовая взаимозависимость: наличие одного продукта заставляет потребителя заинтересоваться другим продуктом. Корпорация обладает мощным потенциалом усилить такой интерес потребителя, инвестируя в развитие инфраструктуры сложившегося или возможного сообщества поставщиков, клиентов и сторонних разработчиков, которые производят или могут произвести товары и услуги, стимулирующие спрос на продукцию материнской компании венчурного инвестора.

В исследовании [21] описан пример стимулирующих венчурных инвестиций корпоративного фонда Intel Capital, которые уже давно стали инструментом продвижения на рынок продукции корпорации. Еще в начале 1990-х гг. в Intel поняли возможности эффективного взаимодействия со стартапами, разрабатывающими и выпускающими продукты и услуги, которые дополняют микропроцессорную продукцию корпорации. Сотни компаний, которые выпускали видео, аудио и графическое оборудование и программное обеспечение, при получении инвестиции Intel могли расширить объем своих продаж, используя все более мощные микропроцессоры, тем самым развивая спрос на чипы Intel Pentium. Стимулирующие корпоративные венчурные инвестиции в случае c Intel, были направлены на увеличение доходов за счет увеличения продаж при использовании текущего стандарта операционной системы Wintel.

Фонд Intel смог эффективно контролировать более 800 инвестиций, которые были сделаны за последние десять лет в соответствии с инвестиционной стратегией корпорации. Для Intel стратегическая ценность при принятии решений об венчурных инвестициях была связана 
не с возможностью координации своих текущих операций в деятельности поддержанных компаний, а с ростом спроса на собственные продукты, который создавался продукцией портфельных компаний. При этом не требовалось тщательно следить за каждой инвестицией, потому что интересы роста бизнеса и контроль производительности носят взаимный характер как для инвестора, так и для менеджмента портфельных компаний. В данном случае высокая эффективность корпоративных венчурных инвестиций была связана с получаемыми стратегическими преимуществами и давала основания Intel продолжать этот тип взаимодействия с различными стартапами, несмотря на неоднократные инвестиционные потери.

Инвестиции, сделанные фондом корпорации Merck, иллюстрируют другой вид стимулирующих инвестиций, проанализированных в этом исследовании [21]. Целью корпоративных венчурных инвестиций стала поддержка технологий, способных повысить доходность, совершенствуя способ ведения текущего бизнеса корпорации, а не увеличение спроса на продукцию Merck. В описанном случае КВФ финансировал стартап-компании, в которых разрабатывали способы ускорении процесса набора пациентов для клинических испытаний новых лекарств для сокращения сроков их проведения. Фактически, инвестор ставил перед стартапами, как исполнителями, задачу и, если они справятся с ней, то Merck будет внедрять в свою деятельность разработанные и апробированные методы, проводя требуемые клинические испытания, необходимые для получения соответствующего разрешения и продвигая на рынок свои лекарства быстрее конкурентов. Для запатентованных лекарственных средств скорость продвижения и продаж имеет принципиальное значение в связи с ограниченностью срока действия патентов. Отдача от венчурных инвестиций для корпорации в данном случае не в получении финансовой прибыли, а в оптимизации бизнес процессов (ускорении набора пациентов), peaлизации своих стратегических преимуществ, что, в конечном счете, по оценкам компании, должно принести Merck миллионы долларов в месяц.
Вместе с тем, стимулирующие венчурные инвестиции также имеют свои пределы. Ограничения формирует развитие рынка. Если затраченные средства смогут помочь захватить значительную часть растущего рынка, и в конкурентной среде не появятся более эффективные решения, то стимулирующие инвестиции будут оправданы. Конкурентные позиции Intel настолько сильны, что можно прогнозировать развитие ситуации и планировать реализацию передовых микропроцессоров, выращивая свою рыночную экосистему. Аналогична ситуация и для Merck, у которой устойчивое положение на рынке лекарственных средств не вызывало сомнений, и можно было инвестировать в усиление своей позиции, не опасаясь внезапного появления мощного конкурента, что привело бы к потере затраченных средств.

Третий, дополняющий тип корпоративных венчурных инвестиций используется с целью достраивания стратегии текущего бизнеса материнской компании [21]. Для инвестиций выбираются стартапы, тесно связанные с операционными возможностями материнской компании и ничего не предлагающие по улучшению ее текущей стратегии. Однако при изменении рыночной среды возможно изменение стратегии корпорации и новый стартап станет стратегически важным. Это своеобразный опцион, который может реализоваться при изменении стратегии корпорации или изменении ее стратегии. Венчурные инвестиции должны определить потенциал развития корпорации и могут принести значительно большие финансовые доходы, чем сумма затрат на портфельную компанию.

В этом случае корпорация получит анализ нового рынка, который можно изучить только при новом наборе клиентов с их сервисными потребностями, отличающимися от обслуживания текущих рынков. Инвестирование в стартап, желающий и способный войти в эту неизведанную территорию - продажу реальных продуктов реальным клиентам, предоставляет информацию, которая никогда не могла бы быть почерпнута с помощью теоретических методов исследования рынка. Отдача от таких инвестиций в своеобразную разведку нового стратегического курса должна быть финансовой, но при этом прорабатывается стратегическое 
целеполагание. Такой тип венчурных инвестиций дополняет достоинства привлеченных инвестиций и для инвестора, и для портфельной компании, причем как в финансовом, так и в стратегическом смысле.

Если речь идет о прочной операционной связи между корпорацией и ее стартапом, то это может происходить в форме обмена технологиями, что иллюстрирует кейс корпорации Lucent Technologie, проанализированный в исследовании [21]. В корпорации сложилась практика разделения производственных мощностей и каналов продаж с новыми независимыми предприятиями с целью повышения эффективности собственных производственных и дистрибьюторских операций и достижения более высокой отдачи.

Фонд Lucent Technologies выбрал инвестиционную стратегию, при которой отбираются портфельные компании, тесно связанные с операционными возможностями корпорации, но не с ее текущей стратегией. Для этого выявляются недоиспользуемые технологии в лабораториях компании Bell и наиболее перспективные из них выделяются в качестве независимых стартапов, которые затем получают венчурные инвестиции. Причем КВФ привлекает и других инвесторов на последующих раундах финансирования Приведенные в исследовании данные показывают примеры результатов инвестирования, когда разработки стартапов стали стратегически ценными для корпорации в связи с изменением рынка, тем более, что полученные результаты при создании технологии позволили больше продвинуться, чем предполагалось первоначально.

В частности, авторы исследования [21] описывают пример стартапа Lucent Digital Video, который разрабатывал аналого-цифровые преобразователи, позволяющие перемещать аудио и видео контент в аналоговых сетях. После того, как продукты новой компании успешно вышли на рынок, Lucent стал продавать собственное оборудование в сочетании с ними. Результаты такого взаимодействия и бурное развитие цифровых технологий открыли для Lucent новые стратегические перспективы, поэтому корпорация снова начала сотрудничество с успешным стартапом. Ключевая стратегическая выгода стала понятной Lucent после получения за счет венчурных инвестиций результатов доработки технологии, созданной ранее в корпорации. Потому идентификация потенциально успешных исследований, создание и инвестирование стартапа при отслеживании в бизнес-подразделении получаемых результатов, для выявления новых перспектив для корпорации - это политика KBФ Lucent.

Авторы исследования [21] считают четвертым, пассивным типом корпоративных венчурных инвестиций, когда стартапы не связаны с собственной стратегией корпорации и слабо связаны с ее операционными возможностями. В этом случае корпорация просто выступает в роли инвестора, и как бы высоко ни оценивались ее технологический опыт и знания рынка, преимуществ перед другими инвесторами, у корпоративных венчурных инвестиций в этом случае не возникает. Потому ничего кроме предполагаемой в будущем продажи портфельной компании при таком инвестировании не стоит ожидать, причем уже идет речь о финансовой прибыли на рынке прямых инвестиций, на котором КВФ не входят в число лидеров по доходности.

Необходимо отметить, что при пассивном типе корпоративного венчурного инвестирования, возможно, возникнут обвинения менеджеров КВФ в нецелевом использовании средств акционеров, так как в таком случае инвестиции не соответствуют корпоративным стратегическим целям и ее операционными возможностям. Имеется немало иных способов получения дохода при финансировании компаний на ранних стадиях, не прибегая к помощи КВФ. Акционеры корпорации в КВФ обычно занимают позиции пассивных инвесторов и стремятся к выходу, если рынки не показывают ожидаемого роста. Новые инвестиции поддерживаются ими, когда экономический рост заметен или ожидается с большой вероятностью.

Приведенный анализ позволяет сделать вывод, что для корпоративного венчурного капитала самое большое значение имеют стимулирующие и дополняющие инвестиции, потому что они могут принести значительные преимущества для материнской компании. Однако в периоды снижения финансовых доходов такие инвестиции возрастают в цене и, следовательно, 
становятся менее привлекательными, по мнению акционеров и менеджмента корпорации, по сравнению с другими традиционными механизмами развития бизнеса. Например, выглядят предпочтительнее рекламные расходы, которые компания может использовать для продвижения своей продукции. Согласно инвестиционным решениям таких компаний, как Intel и Merck, стимулирующие и дополняющие инвестиции могут принести долгосрочные выгоды.

Вместе с тем, нельзя не отметить, что у каждого типа венчурных инвестиций имеются свои преимущества и недостатки для корпорации. Одни эффективны при экономическом росте, а другие помогают снизить потери при экономическом спаде и найти новые пути развития.

В табл. 1 показано шесть способов, которыми различные типы корпоративных венчурных инвестиций могут генерировать рост бизнеса в материнских компаниях.

С учетом пути развития каждой корпорации, инвестиции во внешние стартап-компании могут обеспечивать рост по многим стратегическим направлениям. Для их реализации нужно в КВФ построить свой инвестиционный портфель для получения скрытых стратегических выгод. Обоснование управленческих решений при таком инвестировании должно основываться на ясном понимании стратегических перспектив и операционных возможностей корпорации, независимо от планов роста в настоящем или будущем. В таком случае корпоративные венчурные инвестиции, в конечном счете, будут генерировать рост ценности для ее акционеров.

\section{ЗАКЛЮЧЕНИЕ}

В представленном обзоре отечественных и зарубежных публикаций определены успешные зарубежные практики корпоративного венчурного инвестирования, которые позволяют уточнить критерии устойчивости и требования для достижения стабильного функционирования корпоративных фондов. Принципиальное значение имеет согласованность цели фонда с корпоративными целями материнской компании, непрерывность функционирования

\section{Способы генерации роста бизнеса корпоративными венчурными инвестициями}

\begin{tabular}{|c|c|c|c|}
\hline $\begin{array}{c}\text { Способ } \\
\text { генерации }\end{array}$ & Инвестиции & Тип & Пример \\
\hline $\begin{array}{l}\text { Продвижение } \\
\text { стандарта }\end{array}$ & $\begin{array}{l}\text { В стартапы, производящие продукты } \\
\text { и услуги, которые способствуют внедре- } \\
\text { нию стандартных технологий, которыми } \\
\text { владеет или поддерживает корпорация }\end{array}$ & управляющий & $\begin{array}{l}\text { Инвестиции Microsoft в компа- } \\
\text { нии, поддерживающие .Net, его } \\
\text { архитектуру интернет-сервисов }\end{array}$ \\
\hline $\begin{array}{l}\text { Стимулирование } \\
\text { спроса }\end{array}$ & $\begin{array}{l}\text { В стартапы, разрабатывающие дополнитель- } \\
\text { ные продукты и услуги, повышающие спрос } \\
\text { на собственные продукты корпорации }\end{array}$ & дополняющий & $\begin{array}{l}\text { Инвестиции Intel в компании, } \\
\text { для продуктов которых требуется } \\
\text { процессор Pentium }\end{array}$ \\
\hline $\begin{array}{l}\text { Использование } \\
\text { недоработанных } \\
\text { технологий }\end{array}$ & $\begin{array}{l}\text { В компании, чтобы коммерциализировать } \\
\text { недоработанную и нестратегическую } \\
\text { технологию }\end{array}$ & стимулирующий & $\begin{array}{l}\text { Инвестиции Lucent в компании, } \\
\text { построенные вокруг технологии, } \\
\text { которую Lucent считает несоответ- } \\
\text { ствующей своей текущей стратегии }\end{array}$ \\
\hline $\begin{array}{l}\text { Эксперименты } \\
\text { с новыми } \\
\text { возможностями }\end{array}$ & $\begin{array}{l}\text { В предприятиях, разрабатывающих } \\
\text { интересные новые бизнес-процессы, } \\
\text { не связанные с текущими или } \\
\text { конфликтующие с ними }\end{array}$ & стимулирующий & $\begin{array}{l}\text { Инвестиции Сisco в коммуника- } \\
\text { ционные технологии, которые } \\
\text { она затем приобретает } \\
\text { и развертывает в корпорации }\end{array}$ \\
\hline $\begin{array}{l}\text { Разработка } \\
\text { технологии } \\
\text { резервного } \\
\text { копирования }\end{array}$ & $\begin{array}{l}\text { В компаниях, разрабатывающих альтер- } \\
\text { нативные технологии, как хеджирова- } \\
\text { ние против текущего технологического } \\
\text { направления }\end{array}$ & стимулирующий & $\begin{array}{l}\text { Инвестиции Intel в разработку } \\
\text { сетевой технологии, которая } \\
\text { могла бы заменить технологию, } \\
\text { в которой участвует Intel }\end{array}$ \\
\hline $\begin{array}{l}\text { Изучение } \\
\text { стратегических } \\
\text { пробелов }\end{array}$ & $\begin{array}{l}\text { В компаниях, обслуживающих клиентов } \\
\text { на новых рынках, тем самым обеспечивая } \\
\text { показатель потенциала этих рынков }\end{array}$ & стимулирующий & $\begin{array}{l}\text { Инвестиции Panasonic } \\
\text { в стартапы, направленные } \\
\text { на конвергенцию домашних } \\
\text { вычислений и развлечений }\end{array}$ \\
\hline
\end{tabular}

Источник: [21] 
фонда, демонстрирующего преемственность в отношении стратегии, инвестиционного фокуса и основной команды, а также финансовая устойчивость, позволяющая быть стабильным партером портфельным компаниям в течении всего их жизненного цикла.

При этом во всех проанализированных исследованиях подчеркивается, что КВФ не является инструментом финансовых спекуляций для погони за прибылью, чем кардинально отличается от остальных венчурных фондов, и должен выполнить главную, поставленную перед ним задачу: не пропустить технологические тенденции, имеющие важное значения для развития учредившей фонд корпорации. Созданный венчурный фонд является для корпорации инструментом поиска, развития, трансфера технологий, продуктов и клиентов.

Основные отличия корпоративных и, так называемых, независимых венчурных фондов, учрежденных свободными инвесторами, отражают различные цели, сферы деятельности, источники финансирования, правовой статус, системы вознаграждения менеджмента и подотчетность. К уникальным особенностям корпоративных фондов в сравнении с независимыми фондами необходимо отнести более длинные инвестиционные горизонты, поддержку индустрии и технологии от материнских компаний, что позволяет обеспечить сравнительно лучшую технологическую поддержку и быть более отказоустойчивым к стартапам, которые они финансируют.

Вместе с тем, КВФ необходимо получать ресурсы от корпоративных учредителей, что обуславливает их ориентацию больше на повышение эффективности деятельности материнской организации, чем на рост капитализации инвестируемых компаний. Проведенный анализ показывает, что корпоративные венчурные инвестиции способны лучше развивать инновации в тех случаях, когда имеет место технологическое соответствие между специализацией материнской компании и инвестируемой компании. В таких случаях инвестиции становятся управляющими, стимулирующими и дополняющими развитие корпорации, а для стартапа, получившего вместе с венчурными инвестициями технологические и коммерческие ресурсы крупной компании, преимуществом является большая отказоустойчивость по сравнению с независимыми фондами.

При отсутствии технологического соответствия у стартапа с материнской компанией взаимодействие между ними становится невыгодным из-за потенциала конфликта интересов, что может сделать независимый венчурный фонд предпочтительным источником финансирования.

\section{ЛИТЕРАТУРА}

1. The 2018 Global CVC Report (2019) / CB Insights. https://www.cbinsights.com/research/report/ corporate-venture-capital-trends-2017.

2. Утверждён перечень поручений по итогам заседания Комиссии при Президенте по модернизации и технологическому развитию экономики России (2011) / Официальный сайт Президента России. 31.01.2011. http://www.kremlin.ru/acts/ assignments/orders/10305.

3. Поручения по итогам встречи с членами Экспертного совета при Правительстве и представителями экспертного сообщества по вопросу развития инноваций 25 июля 2014 г. (2014) Peзолюция от 9 августа 2014 г. № ДМ-П36-6057. https://docplayer.ru/4 1387569-Porucheniya-poitogam-vstrechi-s-chlenami-ekspertnogo-soveta-pripravitelstve-i-predstavitelyami-ekspertnogo-soobshchestva-po-voprosu-razvitiya-innovaciy.html.
4. Венчурные инвестиции 2018: инфографика (2019) / Incrussia. https://incrussia.ru/understand/infografika-venchurnye-investitsii-2018.

5. Костеев В., Сидорович В. (2016) Управление инновациях в российских компаниях / НП «Клуб директоров по науке и инновациям» в соавторстве с AO «PBK». https://www.rvc.ru/upload/ iblock/0dd/Management_of_Innovations_in_ Russian_Companies.pdf.

6. Rouly J. (2018) Corporate venture investment climbs higher throughout 2018 / TechCrunch. https://techcrunch.com/2018/09/22/corporate-venture-investment-climbs-higher-throughout-2018.

7. Global Corporate Venture Capital Survey 20082009 (2009) / Ernst \& Young. http://www.ey.com/ Publication/vwLUAssets/SGM_VC_Global_corporate_survey_2008_2009/\$FILE/SGM_VC_Ḡlobal_ corporate_survey_2008_2009.pdf. 
8. Lantza J.-S., Sahutb J.-M., Teulonc F. (2011) What is the Real Role of Corporate Venture Capital? // International Journal of Business. V. 16(4). https://pdfs.semanticscholar.org/ae73/93eba6c0 29a048a079902f597df63e3fc962.pdf.

9. Dushnitsky G., Shapira Z.B. (2010) Entrepreneurial finance meets corporate reality: Comparing investment practices and performing of corporate and independent venture capitalists // Strategic Management Journal. V. 31. P. 990-1017.

10. Manso G. (2011) Motivating innovation // Journal of Finance. V. 66. P. 1823-60.

11. MacMillan I., Roberts E., Livada V., Wang A. (2008) Corporate venture capital (CVC) seeking innovation and strategic growth: Recent patterns in CVC mission, structure, and investment / National Institute of Standards and Technology, U.S. Department of Commerce. 2008.

12. Kuratko D. (2009) The entrepreneurial imperative of the 21 st century // Business Horizons. V. 52. P. 421-428.

13. Yang Y., Narayanan V.K., Zahra S.A. (2009) Developing the selection and valuation capabilities through learning: The case of corporate venture capital // Journal of Business Venturing. V. 24 (3). P. 261-273.

14. Hellmann T. (2002) A theory of strategic venture investing // Journal of Financial Economics. V. 64. P. 285-314.
15. Chemmanur T.J., Loutskina E., Xuan Tian (2014) Corporate Venture Capital, Value Creation, and Innovation. The Review of Financial Studies. V. 27. https://scinapse.io/papers/2135074633.

16. Kogan L., Papanikalaou D., Seru A., Stoffman N. (2012) Technological innovation and growth / Working Paper, MIT.

17. Baldi F., Baglieri D., Corea F. (2015) Balancing risk and learning opportunities in corporate venture capital investments: Evidence from the biopharmaceutical industry // Entrepreneurship Research Journal. V. 5 (3).

18. Lee S.U., Kang J. (2015) Technological diversification through corporate venture capital investments: Creating various options to strengthen dynamic capabilities // Industry and Innovation. V. 22 (5). P. 349-374.

19. Chesbrough H., Bogers M. (2014) Explicating Open Innovation. In H. Chesbrough, W. Vanhaverbeke \& J. West, New Frontiers in Open Innovation (1st ed.). Oxford Scholarship Online.

20. Vančura C. (2014) Financial Metrics in Corporate Venture Capital: Enhancing Strategic Value by Focusing on Financial Goals. https://www.kauffmanfellows.org/journal_posts/ financial-metrics-in-corporate-venture-capital.

21. Chesbrough H.W. (2002) Making sense of corporate venture capital // Harvard Business Review. V. 80 (3). P. 90-99.

\section{REFERENCES}

1. The 2018 Global CVC Report (2019) / CB Insights. https://www.cbinsights.com/research/report/ corporate-venture-capital-trends-2017.

2. The list of instructions was approved following a meeting of the Presidential Commission on Modernization and Technological Development of the Russian Economy (2011) / Official website of the President of Russia. 31.01.201 1. http://www.kremlin.ru/acts/assignments/orders/10305.

3. Instructions following a meeting with members of the Expert Council under the Government and representatives of the expert community on the development of innovations dated 25 July 2014 (2014) Resolution dated 9 August 2014 № DM-P36-6057. https://docplayer.ru/41387569-Porucheniya-poitogam-vstrechi-s-chlenami-ekspertnogo-soveta-pripravitelstve-i-predstavitelyami-ekspertnogo-soobshchestva-po-voprosu-razvitiya-innovaciy.html.

4. Venture investments 2018: infographics (2019) / Incrussia. https://incrussia.ru/understand/infografikavenchurnye-investitsii-2018.

5. Kosteev V., Sidorovich V. (2016) Management of innovations in Russian companies / NP «Club of Directors for Science and Innovations» in cooperation with RVC. https://www.rvc.ru/upload/
iblock/0dd/Management_of_Innovations_in_ Russian_Companies.pdf.

6. Rouly J. (2018) Corporate venture investment climbs higher throughout 2018 / TechCrunch. https://techcrunch.com/2018/09/22/corporate-venture-investment-climbs-higher-throughout-2018.

7. Global Corporate Venture Capital Survey 20082009 (2009) / Ernst \& Young. http://www.ey.com/ Publication/vwLUAssets/SGM VC Global corporate_survey _2008_2009/\$FFILE/SGM_VC_ Global_corporate_survey_2008_2009.pdf.

8. Lantza J.-S., Sah̆utb J.-M., Teulonc F. (2011) What is the Real Role of Corporate Venture Capital? // International Journal of Business. V. 16(4). https://pdfs.semanticscholar.org/ae73/93e ba6c029a048a079902f597df63e3fc962.pdf.

9. Dushnitsky G., Shapira Z.B. (2010) Entrepreneurial finance meets corporate reality: Comparing investment practices and performing of corporate and independent venture capitalists // Strategic Management Journal. V. 31. P. 990-1017.

10. Manso G. (2011) Motivating innovation // Journal of Finance. V. 66. P. 1823-60.

11. MacMillan I., Roberts E., Livada V., Wang A. (2008) Corporate venture capital (CVC) seeking innovation 
and strategic growth: Recent patterns in CVC mission, structure, and investment / National Institute of Standards and Technology, U.S. Department of Commerce. 2008.

12. Kuratko D. (2009) The entrepreneurial imperative of the 21 st century // Business Horizons. V. 52. P. 421-428.

13. Yang Y., Narayanan V.K., Zahra S.A. (2009) Developing the selection and valuation capabilities through learning: The case of corporate venture capital // Journal of Business Venturing. V. 24 (3). P. 261-273.

14. Hellmann T. (2002) A theory of strategic venture investing // Journal of Financial Economics. V. 64. P. 285-314.

15. Chemmanur T.J., Loutskina E., Xuan Tian (2014) Corporate Venture Capital, Value Creation, and Innovation. The Review of Financial Studies. V. 27. https://scinapse.io/papers/2135074633.

16. Kogan L., Papanikalaou D., Seru A., Stoffman N. (2012) Technological innovation and growth / Working Paper, MIT.
17. Baldi F., Baglieri D., Corea F. (2015) Balancing risk and learning opportunities in corporate venture capital investments: Evidence from the biopharmaceutical industry // Entrepreneurship Research Journal. V. 5 (3).

18. Lee S.U., Kang J. (2015) Technological diversification through corporate venture capital investments: Creating various options to strengthen dynamic capabilities // Industry and Innovation. V. 22 (5). P. 349-374.

19. Chesbrough H., Bogers M. (2014) Explicating Open Innovation. In H. Chesbrough, W. Vanhaverbeke \& J. West, New Frontiers in Open Innovation (1st ed.). Oxford Scholarship Online.

20. Vančura C. (2014) Financial Metrics in Corporate Venture Capital: Enhancing Strategic Value by Focusing on Financial Goals. https://www.kauffmanfellows.org/journal_posts/financial-metrics-incorporate-venture-capital.

21. Chesbrough H.W. (2002) Making sense of corporate venture capital // Harvard Business Review. V. 80 (3). P. 90-99.

UDC 330.3

Zinov V.G., Yeremchenko O.A. Corporate venture capital investments: features and successful practices

(The Russian Presidential Academy of National Economy and Public Administration, prospect Vernadskogo, 82,

Moscow, Russia, 11957)

Abstract. The review of domestic and foreign publications presents successful practices of corporate venture

investment, which allow to clarify sustainability criteria and requirements for achieving stable functioning of

corporate funds. It is shown that the coherence of the fund's goals with the goals of the parent company, continuity

of operation, continuity in relation to strategy, investment focus and the main team, as well as financial stability,

which allows us to be a stable partner to portfolio companies throughout their entire life cycle, are of fundamental

importance. It is emphasized that corporate venture investments are not an instrument of financial speculation, and

the parent company needs the created venture fund, first, as an instrument for search, development, transfer of

technologies, products and customers. The main differences between corporate and so-called independent venture

capital funds, reflecting various goals, areas of activity, sources of financing, legal status, management remuneration

systems and accountability, are examined.

Keywords: corporate venture capital investment, venture capital, venture capital fund, corporate venture capital

1 fund, startups, mergers and acquisitions, trends.

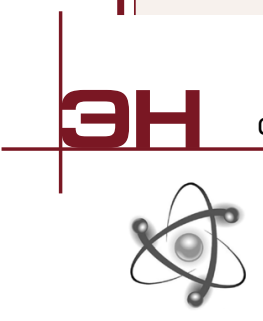

\section{вУзПРОМЭКСпо - 2019} государственных и федеральных целевых программ в сфере науки и промышленности. Организатором выставки является Министерство науки и высшего образования Российской Федерации. Выставка организуется в целях формирования эффективной системы коммуникации в области науки, образования, технологий и инноваций, а также для обеспечения повышения восприимчивости экономики и общества к инновациям и создания условий для развития наукоемкого бизнеса.

«ВУЗПРОМЭКСПО» - это постоянно действующий институализированный форум для реализации стратегии внедрения российских научных разработок в отечественную высокотехнологичную промышленность. Тематикой выставки в 2019 г. является «Наука. Образование. Экономика».

Участниками «ВУЗПРОМЭКСПО» являются более 100 промышленных предприятий, 100 вузов, 40 инжиниринговых центров, которые демонстрируют успешные результаты совместных исследований и научно-технических разработок в рамках Федеральных программ, финансируемых Министерством образования и науки РФ.

Подробную информацию о мероприятии и условиях участия можно получить на сайте http://vuzpromexpo.ru. 